OPEN ACCESS

Edited by:

David Tissue,

Western Sydney University, Australia

Reviewed by:

Cate Macinnis- $\mathrm{Ng}$

School of Biological Sciences, University of Auckland, New Zealand Victor Resco De Dios, Universitat de Lleida, Spain

*Correspondence: Roman Zweife roman.zweifel@wsl.ch

Specialty section:

This article was submitted to

Forest Ecophysiology,

a section of the journal

Frontiers in Forests and Global

Change

Received: 14 August 2018 Accepted: 12 November 2018 Published: 28 November 2018

Citation:

Zweifel $R$ and Sterck F (2018) A Conceptual Tree Model Explaining

Legacy Effects on Stem Growth. Front. For. Glob. Change 1:9. doi: 10.3389/ffgc.2018.00009

\section{A Conceptual Tree Model Explaining Legacy Effects on Stem Growth}

\author{
Roman Zweifel ${ }^{1 \star}$ and Frank Sterck ${ }^{2}$ \\ ${ }^{1}$ Forest Dynamics, Swiss Federal Institute for Forest, Snow and Landscape Research WSL, Birmensdorf, Switzerland, \\ ${ }^{2}$ Forest Ecology and Management Group, Wageningen University, Wageningen, Netherlands
}

Tree species largely differ in the amount of annual stem growth explained by current-year conditions. Historic conditions have been shown to additionally explain a significant fraction of the unexplained variance. So far there is no mechanism described explaining why species differ in such legacy effects, obscuring our understanding of species differences in annual stem growth responses to climate. We present a generic conceptual view on key processes determining stem growth. We link current and historic conditions and their impacts on growth by considering the lifetime of functional organs (leaves and sapwood) and reserves (carbon pool) as a way to quantify legacy effects. We propose how tree species with long organ lifetimes are determined by longer periods of historic conditions than species with short organ lifetimes, and why these species differ in their responses to current conditions. We investigated the hypothesis that including lifetime as variable in a process-based tree model allows for explaining different growth responses to current-year conditions. We show that species with short organ and reserve lifetimes are more sensitive to - and better track - current environmental conditions and therefore respond more strongly to current conditions than species with long lifetimes. Instead, the species with longer organ lifetimes respond more strongly to historic conditions and thus buffer their growth responses to current conditions. We propose the impact of historic environmental conditions being controlled by organ and reserve lifetimes and partially explaining the strength of legacy effects and the explanatory power of current-year environmental conditions on stem growth of different species.

Keywords: legacy effect, organ lifespan, carry-over effect, ecological memory, tree growth, time-lag, acquisitive vs. conservative species

\section{PAST CONDITIONS MATTER}

Variation in stem growth amongst trees, or within the same trees between different years, is driven by a complex of factors, including internal control mechanisms and external environmental variation over multiple years (Monson et al., 2006; Guada et al., 2016). Many studies have shown direct impacts of current environmental conditions on stem growth rates, for example that dry conditions reduce annual stem growth in tree species from temperate (e.g., Weemstra et al., 2013) or tropical forests (e.g., Schippers et al., 2015a). Yet, the annual variation in stem growth of trees is usually explained by $20-40 \%$ from the current-year conditions only (Anderegg et al., 2015; Ogle et al., 2015). The term "legacy effect" (also "carryover effect," "time-lag effect," or "ecological memory effect") has been used to describe the altered responses of plant growth to current conditions by conditions in the past, which is 
proposed to explain at least some of the additional growth variation (Fritts, 1966; Druckenbrod, 2005; Eilmann and Rigling, 2012; Chave, 2013; Levesque et al., 2016).

A recent study very convincingly quantified the legacy effect in plants with a stochastic modeling approach, including timedependent exogenous and endogenous processes-inter aliain trees (Ogle et al., 2015). As an example, stem growth was found to be influenced by precipitation over up to 4 years back in time attributing a much higher explanatory power to precipitation received 1-2 years ago than to the one of the current year. Additionally, the precipitation response was altered by temperature and other environmental variables during the same period. Including legacy effects improved the ability to predict the response variations of growth from below $50 \%$ to over $70 \%$, and thus emphasizes the impact of historical conditions in observed growth rates.

\section{WHAT LINKS CURRENT PHYSIOLOGICAL RESPONSES TO HISTORIC CONDITIONS?}

Both, empirical and modeling studies have shown that history matters in explaining growth over time (Anderegg et al., 2015; Fleta-Soriano and Munne-Bosch, 2016), but a conceptual framework allowing to implement legacy effects in processoriented, mechanistic models is still missing. To put it differently, we can ask where in a tree the information of past conditions takes shape, how can it be quantified, and how does it influence the tree's growth in response to current conditions?

We start from the idea that the entire architecture of a tree including, all its organs and reserves, is the expression of past conditions and consequently influences the actual performance of a tree. However, to understand the respective functional links between these structures and the current stem growth, we need to break this general idea down to specific tissues carrying information from the past to the present. We can think of at least four structures which potentially serve as locations for historic information and which can be directly linked to growth processes: the buds, the leaves, the sapwood, and the stored carbon reserves (Figure 1). We distinguish between resource allocation structures, i.e., organs such as buds, leaves, and the sapwood, and a reserve storage location for carbon located in manifold above- and below-ground organs over the entire tree.

\section{Buds}

Buds fully rely on conditions of the period when they are built and they carry this information, i.e., the max number of leaves or the maximum leaf area (Yang and Midmore, 2005), on to the presence with new shoots in a tree. Buds are thus one of the locations in a tree where past endogenous and exogenous conditions are turned into a physical structure determining the current tree performance in terms of building new leaf area (Dobbertin et al., 2010) and later on in terms of gas exchange and via the subtly balanced leaf-to-sapwood ratio also stem growth (Zweifel et al., 2006; Schippers et al., 2015b; Sterck and Zweifel, 2016; Fan et al., 2017). In the following modeling scenarios, we deal with trees that build buds only once per year but the proposed concept could also be adapted for species with indeterminate bud growth, reported e.g., for eucalypts. In such cases, however, a potential carry-over effect via buds would be reduced to a much shorter timespan than 1 year covering the period between building the buds and flushing.

\section{Leaves}

Leaves remain functional for several months in deciduous trees and up to multiple years in evergreen trees, depending on the species (Kikuzawa and Lechowicz, 2011). The lifetime of leaves has not only a direct effect on a quick or slow return of investment of nutrients and dry mass (Wright et al., 2004), it is further coupled to year-specific functional leaf traits depending on the historic environmental conditions under which the leaves where built. Spruce trees for example are reported to carry needles on the same branch that were produced over more than 10 successive years (Kayama et al., 2007) and also evergreen broadleafed trees maintain their leaves for more than one season. In those species, the total of all leaves and its performance is a product from several years with each year producing different leaf characteristics like the leaf shape, the leaf thickness, the leaf area, and the distribution of leaves on the new shoots and also within the crown. In this way, any leaf cohort contributes to the current assimilation and transpiration-and finally to the growth performance-with (slightly) different responses to the current conditions due to its historic background. Thus, the leaves build another direct link to the past. The longer the leaves live the more years back in time contribute to the current physiological performance of an entire crown. Evergreen tree species with long leaf-lifetimes are consequently considered to have a much stronger legacy effect via the leaves to the stem growth than deciduous species.

\section{Sapwood}

Sapwood, another essential resource allocation structure, is usually maintained for more than one year. Oak species, however, belong to the group of ring-porous species with the smallest amount of active tree rings, whereas other broad-leaf species such as beech, and most conifers keep their old sapwood for many years, up to decades (Cermak et al., 1992). These latter species thus have a sapwood structure built and adjusted to the conditions over many years of the past. A wide range of sapwood lifetimes is also found in the tropics where tree species vary in sapwood age ranging from a few years to multiple decades (Van Der Sande et al., 2015). Every year produces a new ring of sapwood with (slightly) different traits including the sapwood area but also its functional characteristics like the hydraulic conductance. All functional tree rings together determine the efficiency of the water transport under the current conditions. In this work, we interpret sapwood as the functional wood along the pathway from the roots up to the twigs. Consequently, the overall quality and quantity of this organ depends on every single year the individual rings were built, and the more years that are involved the longer is the period and its respective conditions determining the physiological response to the current conditions analog to the argumentation about the leaves. 


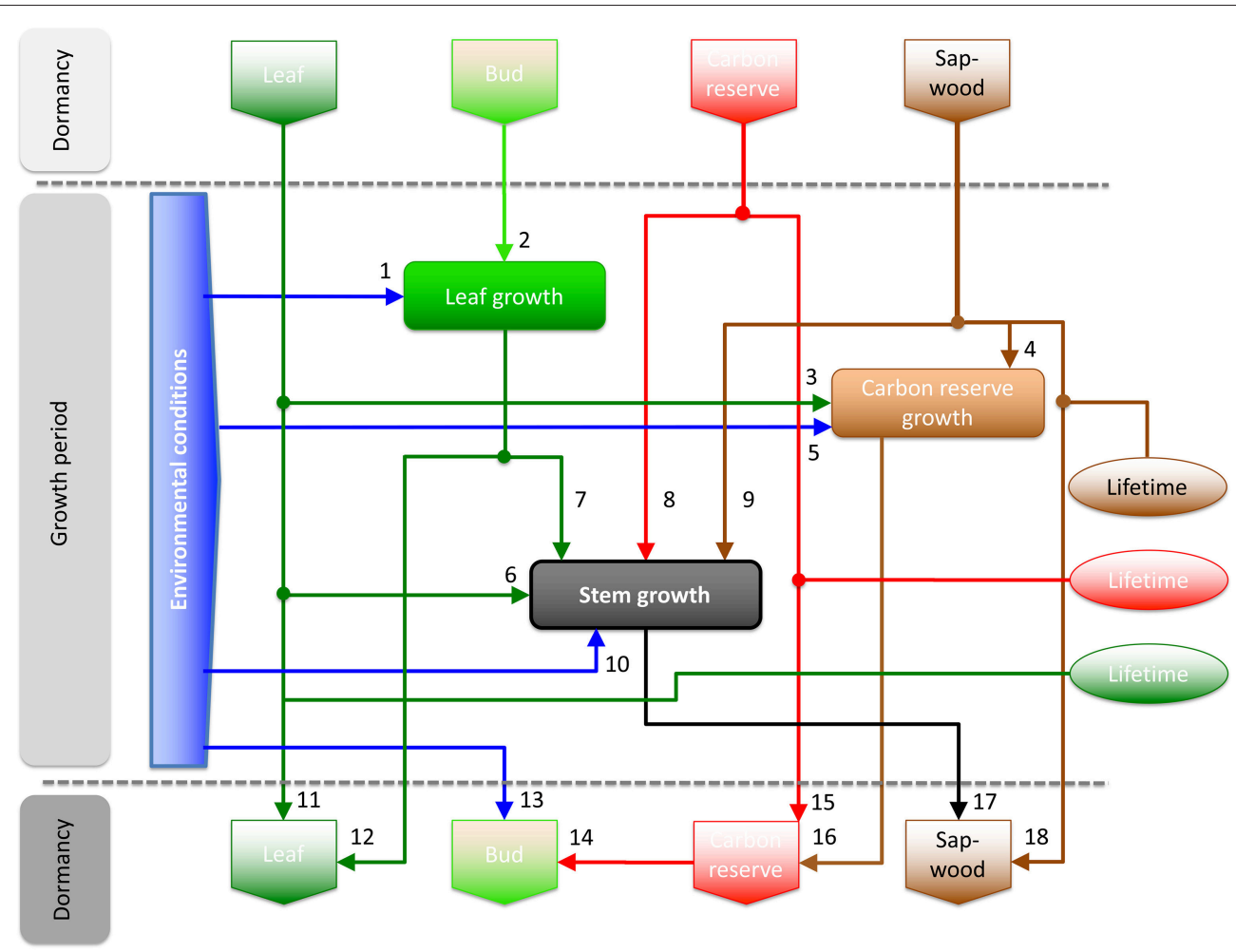

FIGURE 1 | A conceptual, process-oriented model for the performance of trees in a dynamic environment capturing key processes underlying stem growth. Pre-set status of buds, leaves, sapwood, and carbon reserves are the starting points of the iterative simulations with a 1-year time step. Processes respond to current environmental conditions altered by these status, i.e., trait qualities gathered over the respective lifetimes of organs and reserve. Lifetimes define the longevity of the respective structures but also the fraction of them that is abandoned every year. The status of leaves (e.g., leaf area, photosynthetic capacity), buds (e.g., bud size, vernation), sapwood (e.g., sapwood area, hydraulic conductance), and carbon reserves (e.g., quantity, availability) are assumed to be constant during the dormancy period. In fact, this dormancy period could refer to winters in temperate zones and dry periods in tropical zones. In environments with no dormancy period, the dormancy period reduces to zero and the model assumes a full annual cycle with an arbitrary start and end date. Arrows refer to positive functional cause-effect relationships in the direction of the arrow. Stem growth is determined by the status of the environment (arrow 10), the leaves (6), the leaf growth (7), the carbon reserves (8), and the sapwood (9). We assume that the environmental conditions determine the water relations and assimilation processes in trees without delay (1, 5, $10,13)$, meaning that these processes are closely linked to the status of the environmental conditions. Rich environmental conditions can thus be interpreted as high assimilation rates, good water supply, and thus high turgor pressure that allows for growth. Impacts of the leaves (6) and current year leaf growth (7) on the stem growth can be interpreted as being coupled in the signaling via the plant hormone auxin, which is produced in the crown and stimulates stem growth (Dengler, 2001; Zweifel et al., 2006). Sapwood status like sapwood area and conductance (9) contributes to the efficiency of water transport and support growth. And finally the carbon reserves, respectively, their quantity and availability (8) are reported to be a driver for growth, since actual growth hardly ever is directly fed by actual assimilation only (Hoch et al., 2003; Gessler and Treydte, 2016).

\section{Carbon}

Carbon is assimilated in leaves and other organs containing chlorophyll (Vandegehuchte et al., 2015) and is redistributed and used within a plant for, e.g., respiration to maintain the physiological processes in living cells or the construction of new cells, i.e., growth. However, carbon is also stored in organs all over the tree (Monson et al., 2006; Martinez-Vilalta et al., 2016; Galiano et al., 2017). Recent studies have shown that the age of stored carbon extents to multiple decades (Carbone et al., 2013; Richardson et al., 2013, 2015; Gessler and Treydte, 2016). Further, it has been shown that the current year biomass is only partially built of current year assimilates, the rest is taken from internal carbon pools (Hoch et al., 2003). This means that conditions over years or even decades shape the stored carbon quantity, its distribution within a tree, and its accessibility. Thus, we can think of different qualities and quantities of the carbon pool serving the current physiological performance of a tree dependent on the years involved in building it up, analog to the organs discussed above. In line with this argumentation, we assume that different environmental conditions of the past affect the amount and availability of the stored carbon and as such the actual stem growth in trees (Martinez-Vilalta et al., 2016; Galiano et al., 2017).

\section{LIFETIMES OF ORGANS AND RESERVES}

Key to the above-mentioned reflections about where in a tree past conditions get stored and how they determine the current physiological performance, e.g., growth, is the lifetime of organs and reserves. The longer the lifetime is the strongerwe hypothesize-is the impact of historic conditions on the current physiological response and the more decoupled are growth responses from current-year conditions. We thus ask 

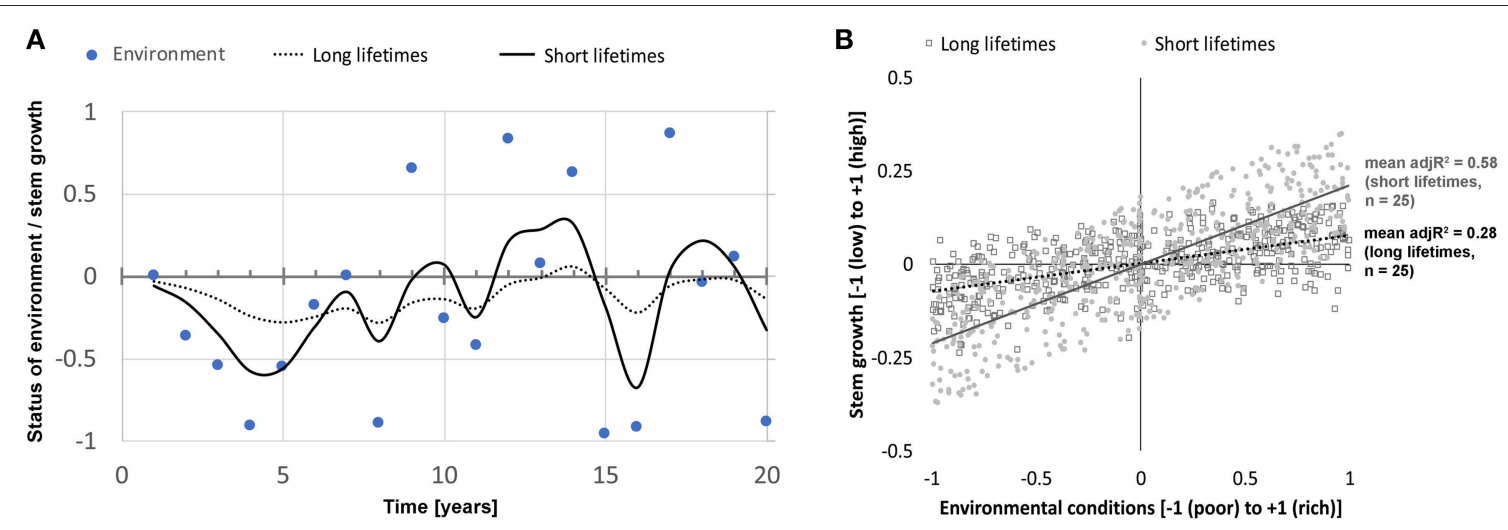

FIGURE 2 | Scenario simulation \#1:25 twenty-year periods with randomly set environmental conditions and the respective stem growth performances to test the explanatory power of current-year environmental condition on stem growth. (A) Example for one of these 20-year periods showing the environmental conditions (blue dots) and the stem growth performances for a model species with long organ and reserve lifetimes (10 years each, dotted line, conservative species) and a species with short organ and reserve lifetimes (1 year each, black line, acquisitive species). (B) Explanatory power of the current-year environmental conditions for stem growth is significantly higher for the acquisitive species (mean adj. $R^{2}=0.58$ ) than for the conservative species [adj. $R^{2}=0.28 ; p<<0.001$, Welch two sample $t$-test of $25 \mathrm{adj} . R^{2}$-values obtained from linear models between environmental conditions and stem growth; an initial Shapiro-Wilk normality test showed normal distribution of stem growth data for acquisitive and conservative species (R Core Team, 2016)].

whether the variable "lifetime," which is quantifiable for every organ and reserve, can be used to additionally explain speciesspecific growth responses to current conditions and thus give the reported statistical evidence for the impact of historic conditions a direct link to tree physiology. The lifetime of organs and reserves directly defines how long historically built traits remain in the system and consequently over what time structures from the past can affect current (growth) performances. Further the variable "lifetime" not only determines over how many years functional structures are accumulated but also the fraction of this structure that is lost every year. For example, a tree with a sapwood lifetime of 5 years replaces $20 \%$ of its structure every year, the rest remains functional. This means, that the impact of the current year's sapwood growth performance on the total physiological tree (water relations) performance should be less in trees with a longer sapwood lifetime. A similar argumentation can be followed for the other organs and reserves carrying over information from multiple years to the present.

\section{A CONCEPTUAL GROWTH MODEL}

In order to test our ideas, we developed a conceptual growth model including the variable "lifetime" for the discussed organs and reserves. The model presented here is neither able to cover any possible interaction between environment and physiological responses nor being complete in terms of potential components involved. However, the model proposed here summarizes a number of whole tree key processes underlying stem growth (Figure 1) and is supposed to be able to catch the main dynamics of physiological processes related to it. Our conceptual model represents a functional network that simulates stem growth from a tree status, where the tree status results from long-term positive and negative impacts of the environment on organ and reserve production and on species-specific organ lifetimes.
The model simulates the key processes in one-year steps from the status of buds, leaves, sapwood, and carbon reserves in spring leading to new status of all the components in autumn. Stem growth in the model directly depends on the status of environmental conditions (arrow \#10 in Figure 1), leaves (\#5 and 6 ), carbon reserves (\#8), and sapwood (\#9). Tree water related processes, i.e., stomatal regulation, transpiration, sapflow, and water storage processes are included in the arrow $\# 10$ because these processes are assumed to be closely linked to environmental conditions and not inducing own response delays in growth on an annual resolution. The same is assumed to be true for the carbon assimilation which also runs in parallel with the status of the environment. Therefore, rich environmental conditions (favorable for supporting an efficient water transport and a high assimilation) are interpreted as high carbon uptake, good water supply, and thus high turgor pressure in the cambium allowing for growth. The hydraulics of a tree are additionally covered via the organ sapwood. As discussed above, the status of the sapwood is closely linked to the hydraulic conductance and contributes to the efficiency of the water transport, lowers the risk of increasing tree water deficits, supports high turgor pressure in the cambium, and thus growth. The impact of sapwood and thus hydraulics on stem growth is altered by the sapwood lifetime. Further, the impact of the leaves (\#5) and current year leaf growth (\#6) on stem growth can be interpreted as signaling via the plant hormone auxin, which is produced in the crown and stimulates stem growth (Dengler, 2001; Zweifel et al., 2006). And finally, the carbon reserves status (quantity or availability) is reported to be a driver for growth, since actual growth hardly ever is directly fed by actual assimilation only (Hoch et al., 2003; Gessler and Treydte, 2016).

In the approach used here, we quantify environmental conditions (from poor to rich), the status of organs and reserves (from low to high), and the performance of growth (from below 


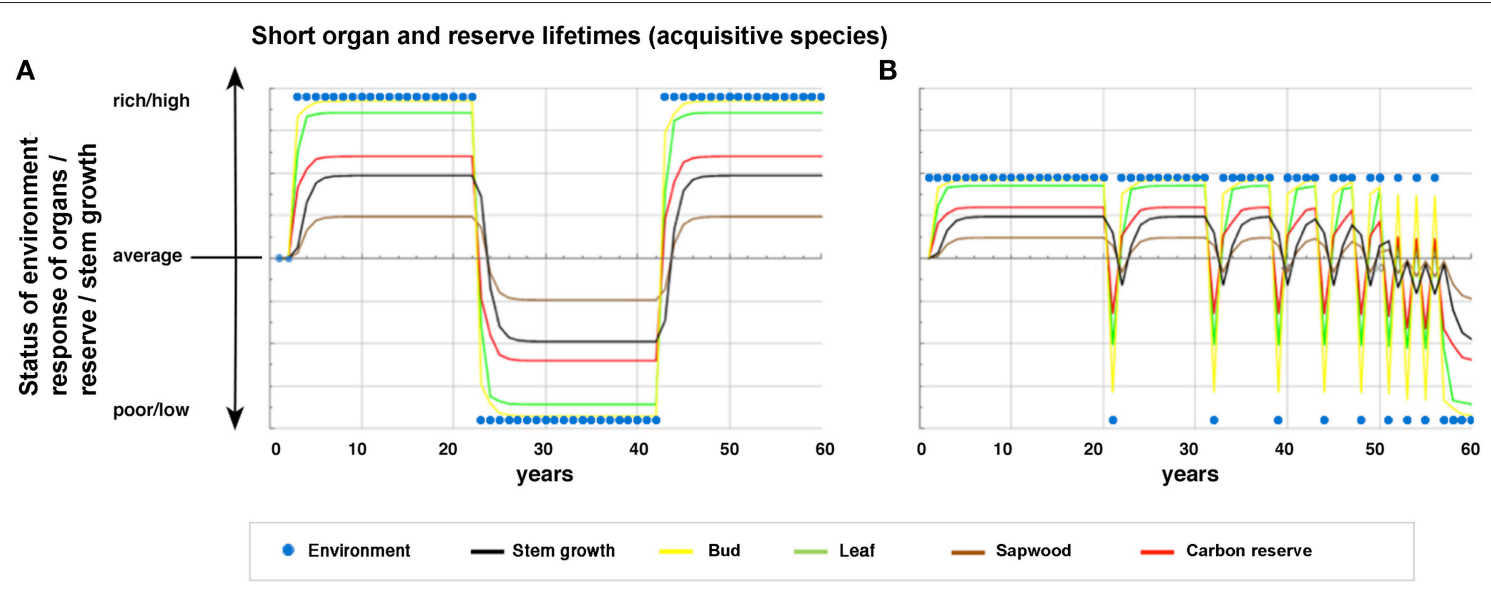

Long organ and reserve lifetimes (conservative species)
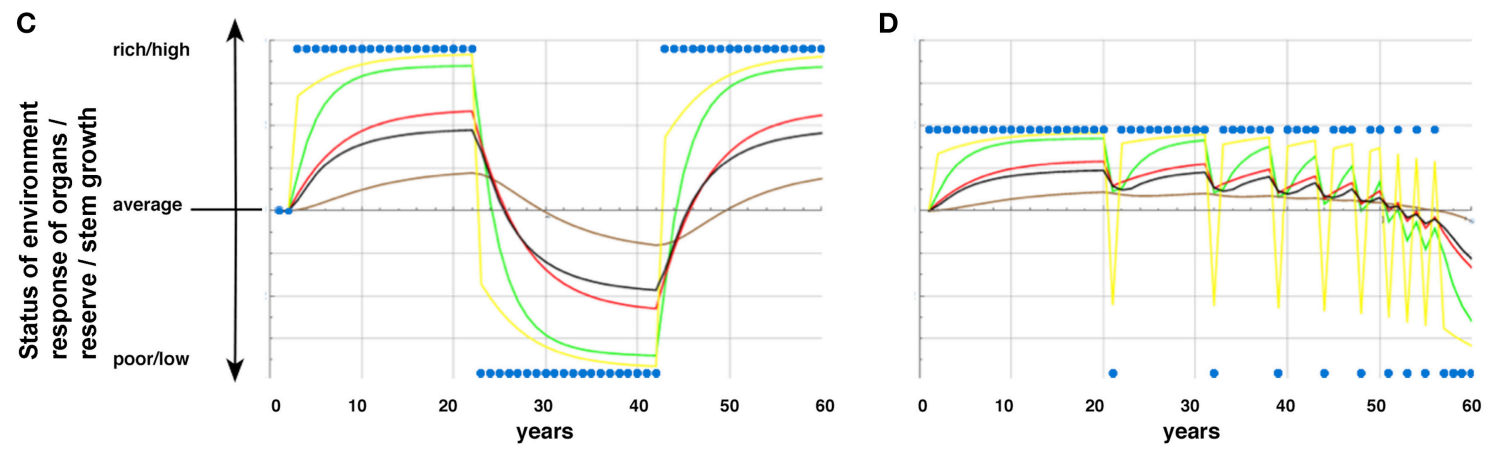

FIGURE 3 | Scenario simulations \#2 and \#3 of annual performance responses of organs, reserves, and growth of trees with (A,B) acquisitive traits (short lifetimes of leaves, sapwood, and carbon reserves; weak legacy effect) and (C,D) conservative traits (Iong lifetimes; strong legacy effect) over time. The environmental conditions (blue dots) as well as all biological variables can deviate from average conditions (resp. size) and can vary between poor (resp. small or low) and rich (resp. large or high). The scenario \#2 $(\mathbf{A}, \mathbf{C})$ simulates the tree's response to a period of 20 rich years, followed by 20 poor years and the return to 20 rich years. The scenario \#3 (B,D) simulates an increasing frequency of poor years for trees living in an environment with generally rich conditions. Any value for organs (bud size, leaf area, sap wood area), reserves (carbon), and annual increment in stem growth above average means a response which indicates a good performance whereas values below average indicate a bad performance.

average to above average) on a relative scale, from -1 to 1 . The model simulates the response of an individual tree. A value of zero means an average environment, status or growth performance. A tree growth performance of zero can be seen as the reference performance, i.e., the performance of a control tree under average conditions. Ecologically, we can associate (1) a poor environment with suboptimal levels of resources for an individual tree and a rich environment with optimal levels of resources. Consequently, the environmental condition "rich" can also mean relatively low temperature, relatively low nutrient availability or even a certain degree of drought because the individual tree simulated is best adapted to these conditions. In this sense, rich means that the conditions are at an optimum for this particular tree individual to physiologically perform best, independent of specific resource values. Generally, rich conditions are not identical for all species (or even individuals) at a certain location, particularly when considering speciesspecific environmental growth niches under naturally occurring competition (see also Korner, 2003).
Ecologically, we can further associate (2) the relative status of organs with the size and the functional performance of organs as the size and number of buds, the total leaf area and photosynthetic- and transpiration capacity of leaves, the sapwood area, and the availability of carbon reserves for growth; and (3) the performance of relative growth as low to high growth rates compared to an average norm growth rate. The organs in the model are parameterized for their respective lifetimes.

Central idea of such analyses include viewing a system as a network of interrelated effects, and leading to emergent output of the system as a whole (Vester, 1999). The model output depends as much on the assumed network of interactions as on the functions themselves. In our case this means that functional relationships between environment, organ and reserve status, and growth, i.e., the processes displayed as arrows with numbers in Figure 1, are determined by positive or negative linear relationships combined with weighting factors when several functions (arrows) point to the same status of organs or reserves or to the same organ growth. 


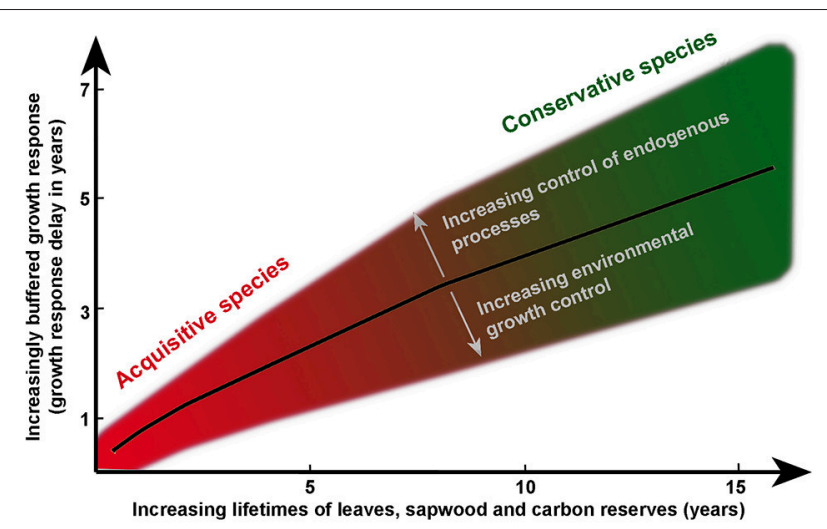

FIGURE 4 | Simulation of the general relationship between lifetimes of leaves, sapwood, and stored reserves and the delay in stem growth [in years]. The stem growth delay is related to lifetimes of organs and reserve and additionally altered by the weighting factors for environmental (exogenous conditions) and endogenous conditions. Increasing the weight of exogenous conditions shortens the growth delay, whereas increasing the weight of endogenous conditions extends it. The black line shows the model parameterization used for the results presented in Figures 2, 3, the gray shadow shows the range of responses when varying the weighting factors (see also Table S1). Acquisitive species are assumed to have short organ and reserve lifetimes and consequently short stem growth delays which means that this species undergoes only weak legacy effects. At the other end of the scale, we propose to find the conservative species with long lifetimes, long growth response delays, and consequently undergoing strong legacy effects.

Despite the fact that there are linear functions used only (for arrows with numbers in Figure 1) and the model is not based on mass- and energy-balances, this system analytical framework can catch non-linear responses of the analyzed system to changing environment. We adopted this approach because it provides a flexible tool to explore the consequences of dynamics in environmental conditions on tree status and stem growth, via the anatomical and physiological memory as it is captured by the lifetimes of organs and reserves. The approach is particularly strong in detecting time-lags when comparing trees that differ in organ lifetimes. Moreover, for basic explorations for this perspective, we consider the responses of trees and impacts of environment in a relative, generic way, with possible, ample application for different trees exposed to different environmental limitations (Figure 1).

\section{EXPLORATIVE SETUP}

We parameterized the model once for a tree with short organ and carbon reserve lifetimes and once for a tree with long lifetimes in order to explore the consequences of different organ lifetimes for the stem growth responses in trees. This choice may be a rough simplification of the reality since we do not expect to find species with having short or long organ and reserve lifetimes only, but showing a mixture of them e.g., short leaf lifetimes but long sapwood lifetimes. However, these two model parameterizations in fact capture a fundamental difference between fast-growing, acquisitive tree species and slow-growing, conservative tree species (Diaz et al., 2016). In this paper, we use the terms acquisitive and conservative species to indicate species that generally differ in lifetimes of organs and reserves, whereas other trait differences (e.g., in leaf photosynthesis) are not considered. Further we do not consider trait changes of historic tissue over time. This simplification may not reflect the total trait spectrum of species, but allows for evaluating the consequences of a key trait (organ and reserve lifetime) for legacy effects on stem growth. Species belonging to these two functional groups with different strategies therefore differ in the niches they occupy (e.g., Sterck et al., 2006, 2014), but the impact of dynamic conditions are rarely considered for them.

In order to investigate the response of the two different parameterizations, three scenarios were run, each with its own sequence of environmental conditions. In the first scenario, random environmental conditions ( 25 twenty-year periods) were used to simulate the growth responses of trees with short and long organ lifetimes in order to quantify how much of the growth response is statistically explicable with current-year environmental conditions (Figure 2).

In the second scenario, trees encounter continuous rich and poor conditions over relatively long periods (20 years) (Figures 3A,C). The scenario allows us to evaluate the stable "equilibrium" status of acquisitive and conservative species under contrasting (rich and poor) conditions.

And finally, the third scenario mimics an increasing frequency of (extreme) poor years (Figures 3B,D) over a total period of 60 years. It may show how trees respond when they more frequently encounter poor years (e.g., drought) as predicted for this century of global change (Intergovernmental Panel on Climate Change, 2014). For more details about functions and parameterizations of the model for the respective scenarios we refer to (Methods S1, S2, Table S1).

\section{ORGAN AND RESERVE LIFETIMES ALTER GROWTH RESPONSES-LINK TO LEGACY EFFECTS}

Tree species with short organ and reserve lifetimes show stem growth responses that are significantly better explained by current-year environmental conditions than the ones of tree species with longer such lifetimes (Figure 2). This supports the link between organ and reserve lifetimes and the strength of the coupling of growth responses to current environmental conditions. The longer these lifetimes are the more decoupled is stem growth from the current conditions, and the less is the explanatory power of the current conditions for growth. This finding is in line with studies quantifying the legacy effect of trees and other biological systems (Anderegg et al., 2015; Ogle et al., 2015) and showing that strong legacy effects reduce the explanatory power of current-year conditions and increase the impact of historic conditions on current physiological processes and emergent stem growth rates.

Further we find that modeled trees with short organ lifetimes (acquisitive species) responded more rapidly to abrupt environmental changes than trees with long organ lifetimes 
(conservative species). After a switch from rich to poor environment, trees with short organ lifetimes performed worse than control trees under average conditions in organs, reserves, and growth, with negative stem growth values in the second year already (Figure 3A). In contrast, trees with long lifetimes maintained an annual stem growth rate above average for several years (Figure 3C). Such strong buffering in growth responses of trees with long organ lifetimes is in line with reports showing that trees such as pines only slowly reduce their large-sized crown despite rapid decrease in needle size following poor conditions (Dobbertin et al., 2010; Feichtinger et al., 2015), and keep stem growth rates above the average for some time (Eilmann and Rigling, 2012; Feichtinger et al., 2017). Keeping the growth increment above the average of a control group (positive values in our scenarios), however, does not mean that there is no straight response possible. As reported in Feichtinger et al. (2017) and also visible in our model tree simulations in Figure 3, stem growth starts to respond right after the disturbance, however the long organ lifetime trees do it much slower and therefore keep increased growth rates above the control for several years. This seeming discrepancy between maintaining a high stem growth rates despite poor environmental conditions appears reasonable in the light of the subtly regulated balance between leaf to sapwood area, suggesting a close coupling of the water demanding leaves, and the growth of supporting sapwood (Schippers et al., 2015b). According to our approach, it is the consequence of a legacy effect of historic conditions on the status of organs and reserves, and finally expressed as a relatively weak growth response to current conditions.

A strong legacy effect seems to be particularly an advantage when poor years occur occasionally under generally favorable growth conditions (Figure 3D). Given that trees with long organ lifetimes thus maintain their vitality during and after extremely poor events, they may face a lower mortality risk of species than the ones with short organ lifetimes, as observed, for example for acquisitive species during and after a drought event in the Amazon in 2005 (Phillips et al., 2009; Schippers et al., 2015a). Thus, while trees encountering persistent low resource levels may have a higher mortality risk (Allen et al., 2010; McDowell and Sevanto, 2010; Cailleret et al., 2017), we suggest, according to our model scenario (Figure 2), that such risks are particularly high for acquisitive species with short organ lifetimes and much less so for conservative species with long lifetimes. Yet, when conditions switch from poor to rich, acquisitive trees with short organ, and reserve lifetimes benefit by their ability to respond more rapidly to the positive improvement of environmental conditions (Figure 2). Such a situation for example occurs after a tree fall in a closed forest, allowing rapid increases in availability of light, soil nutrients and water (Coomes and Grubb, 1998), and leading to an advantage in terms of a rapid growth response for acquisitive tree species hardly affected by legacy effects (Ackerly and Cornwell, 2007). The short ecological memory in terms of having not much structural tissues built during a period of poor conditions (with poor status in terms of supporting stem growth) allows a quick return to vital organs and high growth (above average) as soon as conditions become better. It agrees with the observation that rapidly growing species that monopolize canopy gaps in forests are characterized by shorter leaf lifetimes than shade tolerant tree species that persist in the shaded understory (Wright et al., 2004; Sterck et al., 2006). In contrast, those latter species are known for their slower growth response after an abrupt resource release following a tree fall in a closed forest (Canham, 1988; Sterck and Bongers, 2001). The "equilibrium" status for the modeled conservative trees (with long organ lifetimes) was not even achieved in 20 years in our simulations (Figure 3), whereas the acquisitive species achieved this in $<5$ years. Conservative species with long organ lifetimes and thus undergoing strong legacy effects are suggested to show distinctly stronger and longer-lasting decoupling between stem growth with current environmental conditions (Figure 4) and thus a lower explanatory power of the environment for growth than the acquisitive species (Figure 2).

For annual variation in climate, it is also expected that the annual stem growth of acquisitive species (with short organ lifetimes) show a close relationship with current climatic conditions. An example of a tree species with an exceptionally good match between tree ring width and current year climate is Toona ciliate $\left(R^{2}=0.70\right)$, a ring-porous, deciduous, longlived pioneer tree from tropical areas, recently studied in Thailand (Schippers et al., 2015b). Taking our modeling results into account, we argue that this high explanatory power of environmental conditions for stem growth results from the short lifetimes of leaves ( $<1$ year) and possibly of the functional sapwood of this tree species. In fact, our modeling scenario \#1 shows that short organ and reserve lifetimes in trees lead to significantly higher explanatory power of environmental conditions for growth compared to long ones (Figure 2, Welch two sample $t$-test, $p<<0.001)$.

The above simulations (Figures 2-4) were-for simplicitybased on single parameter settings (see also Table S1) for short organ lifetimes (acquisitive) and long organ lifetimes (conservative) species, for which sensitivities to internal and external controls were kept constant. However, in reality species may differ in combinations of short and long lifetimes of different organs and stored reserves and thus potentially cover multiple combinations of weak and strong legacy effects (Figure 4).

Such ideas however await comparative testing of real data with many tree species that cover a broad range of functional traits such as organ lifetimes, potentially underlying a broad gradient from acquisitive to conservative species (Figure 4). We suggest to relate tree species with different organ lifetimes, e.g., sapwood age and longevity of leaves to the explanatory power of currentyear environmental conditions for their respective annual stem growth. Since stem growth consists of new wood and bark cells that are not in equal proportions produced (Gricar and Cufar, 2008) and thus containing different information (Zweifel et al., 2010, 2016), it may be interesting to do such correlation analyses with both tree ring data and dendrometer-based stem diameter data. Further, manipulative experimental setups including forest trees should allow for testing lags in physiological responses on sudden changes in environmental conditions, e.g., the start or stop of an irrigation treatment, in relation to organ and reserve lifetimes. Such testing will also allow to lift the current consensus on differences between acquisitive to conservative tree species 
in relation to fixed resource niches to a more dynamic and realistic concept of adaptation of trees to dynamic conditions and their relation to memory effects. Furthermore, any type of process-oriented tree model could be extended by the proposed organ lifetime approach, in order to test a potential increase of simulation quality for (growth) processes. And last but not least, it would be interesting to see where except in trees the organ lifetime concept would be able to explain measured variance of biological processes due to legacy effects.

\section{CONCLUSIONS}

We explored the consequences of the lifetimes of functional organs and stored carbon reserves for stem growth responses to current and past conditions. We demonstrated that the period of time a specific organ remains functional may explain legacy effects on stem growth. As described for buds, leaves, sapwood, and carbon reserves, the lifetime of functional organs determines by how many years back in time, the current physiological performance is influenced. The lifetime further defines the fraction of the functional structure that is replaced every year. Our model simulations suggest how the proposed organ and reserve lifetimes allow tree species with short lifetimes to better track the annual changes in climate than conservative species, with long lifetimes, and why they can monopolize favorable conditions after increases in sudden resource availability. We show that the same principles explain why tree species with short organ and reserve lifetimes are more vulnerable to occasionally occurring extreme events and that such species eventually are less able to acclimate (Sterck et al., 2016). This is confirmed by the stronger growth reduction, or increased mortality, of rapidly growing tree species during or after extreme events, such as extreme dry years. And last but not least, our model analyses confirm that lifetimes of organs and reserves determine the explanatory power of current environmental conditions for stem growth. Such confirmative observations remain however still anecdotic. We call for using the increasing amount of information on stem growth and organs lifetimes to test such

\section{REFERENCES}

Ackerly, D. D., and Cornwell, W. K. (2007). A trait-based approach to community assembly: partitioning of species trait values into within- and among-community components. Ecol. Lett. 10, 135-145. doi: 10.1111/j.1461-0248.2006.01006.x

Allen, C. D., Macalady, A. K., Chenchouni, H., Bachelet, D., McDowell, N., Vennetier, M., et al. (2010). A global overview of drought and heat-induced tree mortality reveals emerging climate change risks for forests. Forest Ecol. Manage. 259, 660-684. doi: 10.1016/j.foreco.2009.09.001

Anderegg, W. R. L., Schwalm, C., Biondi, F., Camarero, J. J., Koch, G., Litvak, M., et al. (2015). Pervasive drought legacies in forest ecosystems and their implications for carbon cycle models. Science 349, 528-532. doi: 10.1126/science.aab1833

Cailleret, M., Jansen, S., Robert, E. M. R., Desoto, L., Aakala, T., Antos, J. A., et al. (2017). A synthesis of radial growth patterns preceding tree mortality. Glob. Change Biol. 23, 1675-1690. doi: 10.1111/gcb.13535

Canham, C. D. (1988). Growth and canopy architecture of shade-tolerant trees response to canopy gaps. Ecology 69, 786-795. doi: 10.2307/1941027

Carbone, M. S., Czimczik, C. I., Keenan, T. F., Murakami, P. F., Pederson, N., Schaberg, P. G., et al. (2013). Age, allocation and availability of ideas for different forest biomes by using tree models based on mass and energy balances including ecological memories in the form of lifetimes for organs and reserves. Such model validations and explorations are much required to better understand legacy effects on growth responses in trees to dynamic environments, including to the global changes and increasing extreme events predicted for this century.

\section{DATA AVAILABILITY STATEMENT}

The raw data supporting the conclusions of this manuscript will be made available by the authors, without undue reservation, to any qualified researcher.

\section{AUTHOR CONTRIBUTIONS}

RZ and FS conceived, designed, and executed this study and they wrote the manuscript together.

\section{FUNDING}

This study was funded by the Swiss Federal Institute for Forest, Snow, and Landscape Research WSL with a fellowship for FS. The work was additionally supported by the Federal Office for the Environment FOEN via the project TreeNet (Grant number: 09.0064.PJ/Q351-1 719).

\section{ACKNOWLEDGMENTS}

We thank Arthur Gessler, Sophia Etzold, and Kasia Zieminska for helpful comments and discussions.

\section{SUPPLEMENTARY MATERIAL}

The Supplementary Material for this article can be found online at: https://www.frontiersin.org/articles/10.3389/ffgc.2018. 00009/full\#supplementary-material

nonstructural carbon in mature red maple trees. N. Phytol. 200, 1145-1155 doi: $10.1111 / \mathrm{nph} .12448$

Cermak, J., Cienciala, E., Kucera, J., and Hällgren, J. E. (1992). Radial velocity profiles of water flow in trunks of Norway spruce and oak and the response of spruce to severing. Tree Physiol. 10, 367-380. doi: 10.1093/treephys/10. 4.367

Chave, J. (2013). The problem of pattern and scale in ecology: what have we learned in 20 years? Ecol. Lett. 16, 4-16. doi: 10.1111/ele.12048

Coomes, D. A., and Grubb, P. J. (1998). Responses of juvenile trees to aboveand belowground competition in nutrient-starved Amazonian rain forest. Ecology 79, 768-782. doi: 10.1890/0012-9658(1998)079[0768:ROJTTA]2. $0 . \mathrm{CO} ; 2$

Dengler, N. G. (2001). Regulation of vascular development. J. Plant Growth Regul. 20, 1-13. doi: 10.1007/s003440010008

Diaz, S., Kattge, J., Cornelissen, J. H. C., Wright, I. J., Lavorel, S., Dray, S., et al. (2016). The global spectrum of plant form and function. Nature 529, U167-U173. doi: 10.1038/nature16489

Dobbertin, M., Eilmann, B., Bleuler, P., Giuggiola, A., Pannatier, E. G., Landolt, W., et al. (2010). Effect of irrigation on needle morphology, shoot and stem growth in a drought-exposed Pinus sylvestris forest. Tree Physiol. 30, 346-360. doi: 10.1093/treephys/tpp123 
Druckenbrod, D. L. (2005). Dendroecological reconstructions of forest disturbance history using time-series analysis with intervention detection. Can. J. Forest Res. Revue Can. Recherche Forestiere 35, 868-876. doi: 10.1139/x05-020

Eilmann, B., and Rigling, A. (2012). Tree-growth analyses to estimate tree species' drought tolerance. Tree Physiol. 32, 178-187. doi: 10.1093/treephys/tps004

Fan, Z. X., Sterck, F., Zhang, S. B., Fu, P. L., and Hao, G. Y. (2017). Tradeoff between stem hydraulic efficiency and mechanical strength affects leaf-stem allometry in 28 ficus tree species. Front. Plant Sci. 8:1619. doi: 10.3389/fpls.2017.01619

Feichtinger, L. M., Eilmann, B., Buchmann, N., and Rigling, A. (2015). Traitspecific responses of Scots pine to irrigation on a short vs. long time scale. Tree Physiol. 35, 160-171. doi: 10.1093/treephys/tpu114

Feichtinger, L. M., Siegwolf, R. T. W., Gessler, A., Buchmann, N., Levesque, M., and Rigling, A. (2017). Plasticity in gas-exchange physiology of mature Scots pine and European larch drive short- and long-term adjustments to changes in water availability. Plant Cell Environ. 40, 1972-1983. doi: 10.1111/pce.13008

Fleta-Soriano, E., and Munne-Bosch, S. (2016). Stress memory and the inevitable effects of drought: a physiological perspective. Front. Plant Sci. 7:143. doi: 10.3389 /fpls.2016.00143

Fritts, H. C. (1966). Growth-rings of trees - their correlation with climate. Science 154, 973-979. doi: 10.1126/science.154.3752.973

Galiano, L., Timofeeva, G., Saurer, M., Siegwolf, R., Martinez-Vilalta, J., Hommel, R., et al. (2017). The fate of recently fixed carbon after drought release: towards unravelling $\mathrm{C}$ storage regulation in Tilia platyphyllos and Pinus sylvestris. Plant Cell Environ. 40, 1711-1724. doi: 10.1111/pce.12972

Gessler, A., and Treydte, K. (2016). The fate and age of carbon - insights into the storage and remobilization dynamics in trees. N. Phytol. 209, 1338-1340. doi: $10.1111 / \mathrm{nph} .13863$

Gricar, J., and Cufar, K. (2008). Seasonal dynamics of phloem and xylem formation in silver fir and Norway spruce as affected by drought. Rus. J. Plant Physiol. 55, 538-543. doi: 10.1134/S102144370804016X

Guada, G., Camarero, J. J., Sanchez-Salguero, R., and Cerrillo, R. M. N. (2016). Limited growth recovery after drought-induced forest dieback in very defoliated trees of two pine species. Front. Plant Sci. 7:418. doi: $10.3389 /$ fpls.2016.00418

Hoch, G., Richter, A., and Körner, C. (2003). Non-structural carbon compounds in temperate forest trees. Plant Cell Environ. 26, 1067-1081. doi: 10.1046/j.0016-8025.2003.01032.x

Intergovernmental Panel on Climate Change (2014). Climate Change 2014: Mitigation of Climate Change.

Kayama, M., Kitaoka, S., Wang, W., Choi, D., and Koike, T. (2007). Needle longevity, photosynthetic rate and nitrogen concentration of eight spruce taxa planted in northern Japan. Tree Physiol. 27, 1585-1593. doi: 10.1093/treephys/27.11.1585

Kikuzawa, K., and Lechowicz, M. J. (2011). "Ecology of leaf longevity," in Ecological Research Monographs, ed Kikuzawa, K. and Lechowicz, M. J. (Tokyo; Dordrecht; Heidelberg; London; New York, NY: Springer), 147.

Korner, C. (2003). Limitation and stress - always or never? J. Veg. Sci. 14, 141-143. doi: 10.1111/j.1654-1103.2003.tb02138.x

Levesque, M., Walthert, L., and Weber, P. (2016). Soil nutrients influence growth response of temperate tree species to drought. J. Ecol. 104, 377-387. doi: 10.1111/1365-2745.12519

Martinez-Vilalta, J., Sala, A., Asensio, D., Galiano, L., Hoch, G., Palacio, S., et al. (2016). Dynamics of non-structural carbohydrates in terrestrial plants: a global synthesis. Ecol. Monogr. 86, 495-516. doi: 10.1002/ecm.1231

McDowell, N. G., and Sevanto, S. (2010). The mechanisms of carbon starvation: how, when, or does it even occur at all? N. Phytol. 186, 264-266. doi: $10.1111 / j .1469-8137.2010 .03232 . x$

Monson, R. K., Rosenstiel, T. N., Forbis, T. A., Lipson, D. A., and Jaeger, C. H. (2006). Nitrogen and carbon storage in alpine plants. Integr. Comp. Biol. 46, 35-48. doi: 10.1093/icb/icj006

Ogle, K., Barber, J. J., Barron-Gafford, G. A., Bentley, L. P., Young, J. M., Huxman, T. E., et al. (2015). Quantifying ecological memory in plant and ecosystem processes. Ecol. Lett. 18, 221-235. doi: 10.1111/ele.12399

Phillips, O. L., Aragao, L., Lewis, S. L., Fisher, J. B., Lloyd, J., Lopez-Gonzalez, G., et al. (2009). Drought sensitivity of the amazon rainforest. Science 323, 1344-1347. doi: 10.1126/science.1164033

R Core Team (2016). R: A Language and Environment for Statistical Computing [Online]. Vienna: R Foundation for Statistical Computing. Available online at: http://www.R-project.org/ (Accessed).
Richardson, A. D., Carbone, M. S., Huggett, B. A., Furze, M. E., Czimczik, C. I., Walker, J. C., et al. (2015). Distribution and mixing of old and new nonstructural carbon in two temperate trees. N. Phytol. 206, 590-597. doi: $10.1111 /$ nph. 13273

Richardson, A. D., Carbone, M. S., Keenan, T. F., Czimczik, C. I., Hollinger, D. Y., Murakami, P., et al. (2013). Seasonal dynamics and age of stemwood nonstructural carbohydrates in temperate forest trees. N. Phytol. 197, 850-861. doi: $10.1111 /$ nph. 12042

Schippers, P., Sterck, F., Vlam, M., and Zuidema, P. A. (2015a). Tree growth variation in the tropical forest: understanding effects of temperature, rainfall and CO2. Glob. Change Biol. 21, 2749-2761. doi: 10.1111/gcb.12877

Schippers, P., Vlam, M., Zuidema, P. A., and Sterck, F. (2015b). Sapwood allocation in tropical trees: a test of hypotheses. Funct. Plant Biol. 42, 697-709. doi: 10.1071/FP14127

Sterck, F., Anten, N. P. R., Schieving, F., and Zuidema, P. A. (2016). Trait acclimation mitigates mortality risks of tropical canopy trees under global warming. Front. Plant Sci. 7:607. doi: 10.3389/fpls.2016.00607

Sterck, F., Markesteijn, L., Toledo, M., Schieving, F., and Poorter, L. (2014). Sapling performance along resource gradients drives tree species distributions within and across tropical forests. Ecology 95, 2514-2525. doi: 10.1890/132377.1

Sterck, F., and Zweifel, R. (2016). Trees maintain a similar conductance per leaf area through integrated responses in growth, allocation, architecture and anatomy. Tree Physiol. 36, 1307-1309. doi: 10.1093/treephys/tpw100

Sterck, F. J., and Bongers, F. (2001). Crown development in tropical rain forest trees: patterns with tree height and light availability. J. Ecol. 89, 1-13. doi: $10.1046 / j .1365-2745.2001 .00525 . x$

Sterck, F. J., Poorter, L., and Schieving, F. (2006). Leaf traits determine the growth-survival trade-off across rain forest tree species. Am. Nat. 167, 758-765. doi: $10.1086 / 503056$

Van Der Sande, M. T., Zuidema, P. A., and Sterck, F. (2015). Explaining biomass growth of tropical canopy trees: the importance of sapwood. Oecologia 177 1145-1155. doi: 10.1007/s00442-015-3220-y

Vandegehuchte, M. W., Bloemen, J., Vergeynst, L. L., and Steppe, K. (2015). Woody tissue photosynthesis in trees: salve on the wounds of drought? N. Phytol. 208, 998-1002. doi: 10.1111/nph.13599

Vester, F. (1999). Die Kunst vernetzt zu denken - Ideen und Werkzeuge für einen Umgang mit Komplexität. Stuttgart: Deutsche Verlagsanstalt GmbH.

Weemstra, M., Eilmann, B., Sass-Klaassen, U. G. W., and Sterck, F. J. (2013). Summer droughts limit tree growth across 10 temperate species on a productive forest site. For. Ecol. Manag. 306, 142-149. doi: 10.1016/j.foreco.2013.06.007

Wright, I. J., Reich, P. B., Westoby, M., Ackerly, D. D., Baruch, Z., Bongers, F., et al. (2004). The worldwide leaf economics spectrum. Nature 428, 821-827. doi: 10.1038/nature02403

Yang, Z., and Midmore, D. J. (2005). Modelling plant resource allocation and growth partitioning in response to environmental heterogeneity. Ecol. Model. 181, 59-77. doi: 10.1016/j.ecolmodel.2004.06.023

Zweifel, R., Eugster, W., Etzold, S., Dobbertin, M., Buchmann, N., and Häsler, R. (2010). Link between continuous stem radius changes and net ecosystem productivity of a subalpine Norway spruce forest in the Swiss Alps. N. Phytol. 187, 819-830. doi: 10.1111/j.1469-8137.2010.03301.x

Zweifel, R., Haeni, M., Buchmann, N., and Eugster, W. (2016). Are trees able to grow in periods of stem shrinkage? N. Phytol. 211, 839-849. doi: $10.1111 /$ nph.13995

Zweifel, R., Zeugin, F., Zimmermann, L., and Newbery, D. M. (2006). Intra-annual radial growth and water relations of trees - implications towards a growth mechanism. J. Exp. Bot. 57, 1445-1459. doi: 10.1093/jxb/ erj125

Conflict of Interest Statement: The authors declare that the research was conducted in the absence of any commercial or financial relationships that could be construed as a potential conflict of interest.

Copyright $\odot 2018$ Zweifel and Sterck. This is an open-access article distributed under the terms of the Creative Commons Attribution License (CC BY). The use, distribution or reproduction in other forums is permitted, provided the original author(s) and the copyright owner(s) are credited and that the original publication in this journal is cited, in accordance with accepted academic practice. No use, distribution or reproduction is permitted which does not comply with these terms. 